\title{
Novas espécies de Diplusodon Pohl (Lythraceae) do Planalto Central e Estado de Minas Gerais, Brasil
}

\author{
Taciana Barbosa Cavalcanti ${ }^{1}$
}

Recebido em 9/06/2006. Aceito em 24/02/2007

\begin{abstract}
RESUMO - (Novas espécies de Diplusodon Pohl (Lythraceae) do Planalto Central e Estado de Minas Gerais, Brasil). Quatro novas espécies são descritas e ilustradas para o gênero Diplusodon, que se somam ao alto número de espécies registradas para este gênero no Cerrado brasileiro, mais especificamente para as montanhas que formam a Serra Geral do Paranã, ou Serra Geral de Goiás, reafirmando a região como centro de diversidade genética do gênero. As seguintes espécies são descritas: Diplusodon capitalensis, do Distrito Federal e Goiás, D. chapadensis e D. grahamae, de Goiás, e D. rupestris, de Minas Gerais.
\end{abstract}

Palavras-chave: Diplusodon, Lythraceae, novas espécies, taxonomia, Brasil

ABSTRACT - (New species of Diplusodon Pohl (Lythraceae) from Central Brazil and Minas Gerais State). Four new species are described and illustrated for the genus Diplusodon. These are added to the already high number of species registered for the Brazilian Cerrado, more precisely in the chain of mountains that form the Serra Geral do Paranã or Serra Geral de Goiás, confirming this region as the primary center of genetic diversity of the genus. The following species are described: Diplusodon capitalensis, from the Distrito Federal and Goiás, D. chapadensis and D. grahamae from Goiás, and D. rupestris, from Minas Gerais.

Key words: Diplusodon, Lythraceae, new species, taxonomy, Brazil

\section{Introdução}

Diplusodon é caracterizado por possuir folhas opostas, flores regulares, hexâmeras, períginas, duas bractéolas e um epicálice de seis apêndices. O gineceu é bicarpelar e unilocular com um septo incompleto. $\mathrm{O}$ androceu pode ser diplostêmone, polistêmone ou raramente aplostêmone. O fruto é uma cápsula septicida com sementes aladas.

O gênero Diplusodon apresenta cerca de 80 espécies, distribuídas através da área contínua do Cerrado brasileiro e também nos cerrados da Bolívia (Cavalcanti \& Graham 1996; Cavalcanti \& Graham 2005). As espécies do gênero ocupam diferentes ambientes, incluindo bordas de matas de galeria, campos limpos sobre solo arenoso, cerrado denso com árvores e arbustos altos, cerrados abertos, campos sujos e campos rupestres, mas é neste último que se observa alto número de espécies e endemismos. Do mesmo modo que os ambientes ocupados são diversificados, a diversidade de espécies é alta, sendo o Brasil Central o centro de diversidade genética do gênero (Cavalcanti
2004), mais precisamente na cadeia de montanhas da Serra Geral do Paranã (Estados de Goiás e Tocantins) ou Serra Geral de Goiás.

A realização de recentes coletas nas regiões de cerrados e campos rupestres do Planalto Central do Brasil revelou novas espécies aqui apresentadas, dando continuidade aos estudos sobre a revisão taxonômica do gênero.

\section{Resultados e discussão}

1. Diplusodon capitalensis T.B. Cavalc., sp. nov. Tipo: BRASIL. Distrito Federal: Brasília, Fazenda Água Limpa - FAL, no campo de arnica, 25/V/2003, fl., J.F. Pastore, A.S. Rodrigues, F.F. Miranda-Santos \& J.B.A. Bringel Jr. 610 (Holótipo CEN; isótipos K, MO).

Fig. 1-3

Diplusodon capitalensis praecipue inflorescentia bracteosa, foliis ellipticis vel elliptico-lanceolatis, acrodromis, domatiis manifestis, indumento brevi, albo, denso et appresso facie abaxiali folium et florum (hoc

\footnotetext{
${ }^{1}$ Embrapa Recursos Genéticos e Biotecnologia, Parque Estação Ecológica, Final W5 Norte, C. Postal 02372, 70770-900 Brasília, DF, Brasil (taciana@cenargen.embrapa.br)
} 
character tubum florarem albescentem faciens) distinguenda. Forma foliorum D. lanceolatus Pohl affinis sed absentia ramis accessoriis, segmentis epicalycis brevibus et foliis angustis differt.

Subarbustos 30-40 cm alt., eretos, ramificados, com xilopódio. Ramos superiores ferrugíneos, cilíndricos a subquadrangulares, não alados, pubescentes, tricomas curtos, às vezes vilosos ou estrelados; internós 1,0-4,0 cm compr. Folhas 15-47×5,0-16 mm, decussadas, suberetas, acródromas basais supra-numerárias, coriáceas, subsésseis, canescentes, tricomas de base espessada, curto-vilosos a estrelados misturados, às vezes só estrelados, às vezes só na face abaxial, elípticas a elípticolanceoladas, ápice agudo, margem subrevoluta, base obtusa; nervuras 2-3, domácias presentes; pecíolo 0,5-1,2 mm compr. Diplobótrio a triplobótrio, bracteoso; ramos acessórios ausentes; brácteas semelhantes às

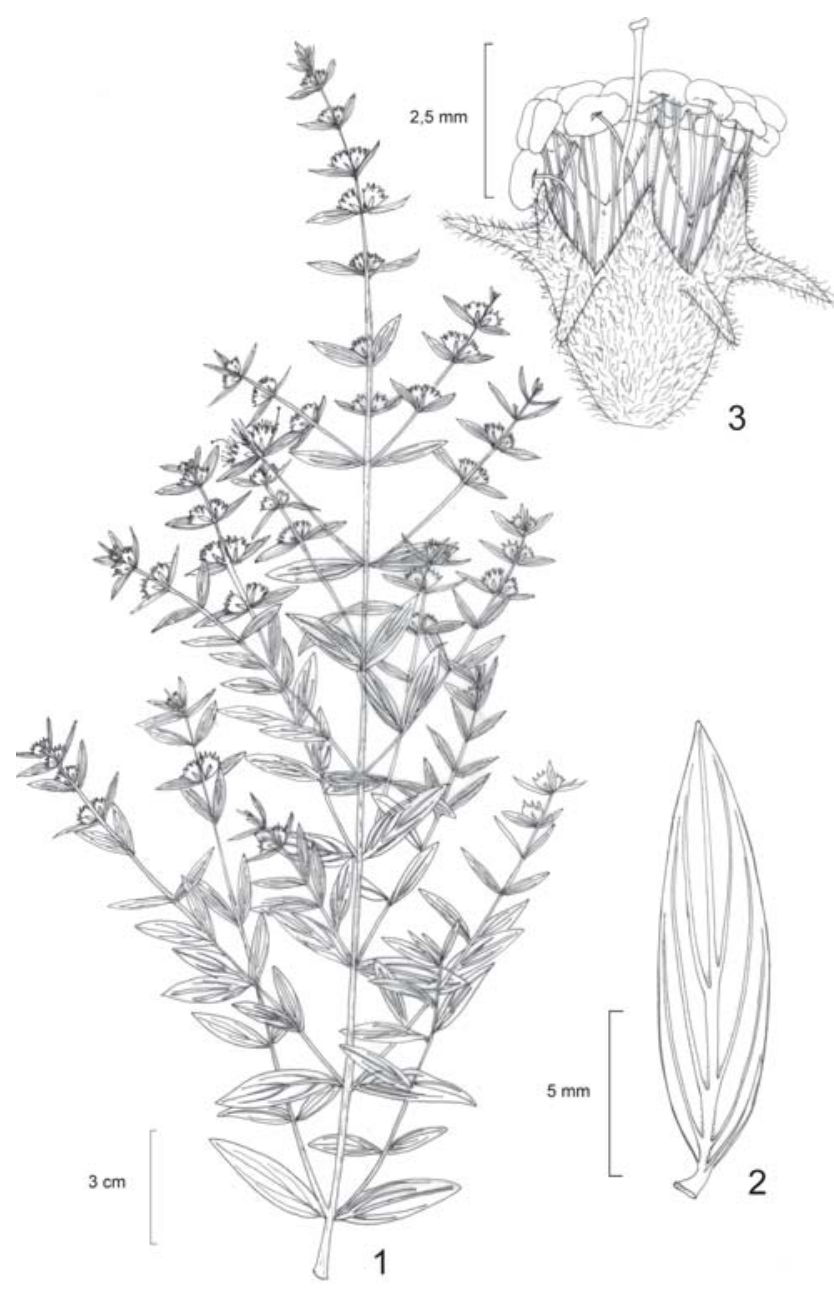

Figuras 1-3. Diplusodon capitalensis T.B. Cavalc. (Pastore et al. 610). 1. Ramo com inflorescência. 2. Folha, face abaxial. 3. Flor, retiradas as pétalas e os profilos (ilustrações elaboradas pela autora). folhas vegetativas em forma e diminuindo de tamanho, eucamptódromas; flores subsésseis, hipopódio ca. 0,5 mm compr., epipódio ca. 0,5 mm compr.; profilos 4,0-5,0 mm compr., ovais a largo-elípticos, ápice obtuso, margem plana, carenados, alcançando o ápice do tubo floral ou ultrapassando pouco; tubo floral 4,8-5,0 mm compr., infundibuliforme, esbranquiçado, coberto por tricomas curto-vilosos, apressos e ascendentes, estrelados; sépalas 2,0-2,9 mm compr., triangulares, não caudadas, curto-ciliadas, tricomas curtos, eretos; segmentos do epicálice 1,9-2,9 mm compr., patentes, cilíndricos, tricomas curtos, eretos; corola 2,5-3,2 cm diâm., lilás, pétalas ca. $13 \times 11 \mathrm{~mm}$, oboval-elípticas; estames 18 , pouco exsertos, porção livre dos filetes ca. 7,0 mm compr.; ovário 1,2-1,5×ca.2,5 mm, obtrapezoidal, glabro, estilete ca. $11 \mathrm{~mm}$ compr., óvulos 25-32. Cápsulas imaturas 2,8-3,0×2,9-3,0 mm, arredondadas, não estipitadas; sementes 10-18.

Parátipos: BRASIL. Distrito Federal: Brasília, proximidades da CAESB, QI 19, Lago Sul, 9/VI/1985, fl., Legre s.n. (UB); Fazenda Água Limpa, 25/V/2003, fl., Pastore et al. 597 (CEN); estrada para o Poço Azul, ao lado do Parque Nacional, 25/V/2003, fl., fr., Pastore et al. 641 (CEN, K, NY, SPF, W); a $32 \mathrm{~km}$ do Cenargen, DF 170, 153' $\mathrm{S}, 4^{\circ} 03^{\prime} \mathrm{W}, 4 / \mathrm{XI} / 1992$, fl., fr., Dias \& Vieira 153 (CEN); ca. 1,5 km W das antenas da Radiobrás, $15^{\circ} 36^{\prime} \mathrm{S}, 48^{\circ} 08^{\prime} \mathrm{W}, 14 / \mathrm{IV} / 1982$, fl., Kirkbride Jr. 4731 (UB). Goiás: Luziânia, Fazenda Légua, 16²1'19"S, 48¹2'35"W, 11/VI/2003, fl., Pereira-Silva et al. 7905 (CEN, MO).

Diplusodon capitalensis apresenta como características mais marcantes a inflorescência ramificada, bracteosa, ou seja, folhas e brácteas diferenciadas, sendo as folhas acródromas basais supranumerárias e as brácteas eucamptódromas. As folhas são elípticas a elíptico-lanceoladas, cobertas por indumento curto-viloso a estrelado, branco e denso, e apresentam domácias. As flores são cobertas pelo mesmo tipo de indumento das folhas, mais denso, deixando o tubo floral com cor esbranquiçada.

Diplusodon lanceolatus Pohl assemelha-se a D. capitalensis pela forma das folhas, mas difere principalmente por apresentar inflorescência pouco ramificada, flores com diâmetro maior $(3,0-4,5 \mathrm{~cm})$, tubo floral não esbranquiçado, folhas sem domácias, e segmentos do epicálice com 4,0-5,5 $\mathrm{mm}$ de comprimento.

Embora a região onde se situa o Distrito Federal tenha sido bastante visitada para coletas, foram encontrados poucos espécimes nos herbários consultados. A nova espécie foi também encontrada 
em Luziânia, Goiás, município vizinho ao Distrito Federal. Em ambas as localidades, a espécie foi registrada em vegetação de cerrado sensu stricto, a 1.000 m s.n.m.

2. Diplusodon chapadensis T.B. Cavalc., sp. nov. Tipo: BRASIL. Goiás: Alto Paraíso de Goiás, Chapada dos Veadeiros, estrada Alto Paraíso de Goiás-Colinas do Sul, a $28 \mathrm{~km}$ do entroncamento da GO-118, 1408'06"S, 4744'04'W, 2/IV/1997, fl., fr., T.B. Cavalcanti, G. Pereira-Silva \& S.A. Graham 2185 (Holótipo CEN; isótipos K, NY, RB, SPF).

Fig. 4-6

Foliis angusto-ellipticis, prophyllis longis, ultra apicem tubi floralis, tubo florali oblongo, segmentis epicalycis patentibus et 18 staminibus distinguenda. Diplusodon macrodon Koehne foliis eucamptodromis affinis sed indumento trichomatibus stellatis, densis, caespitosis, foliis revolutis, 12 staminibus et segmentis epicalycis 5,5-7,0 $\mathrm{mm}$ longis et erectis differt.

Subarbustos 15-25 cm alt., prostrados, não ramificados, com xilopódio. Ramos superiores verdes, cilíndricos, não alados, pubescentes a hirtelos; internós 2,0-3,0 cm compr. Folhas 12-30×3,0-5,0 mm, decussadas, eretas, eucamptódromas, membranáceas a cartáceas, pecioladas, cobertas por indumento branco denso a esparso-pubescente, estreito-elípticas, ápice agudo, margem subrevoluta, base aguda, atenuada; nervuras 2 de cada lado e ao longo da nervura central, inconspícuas em ambas as faces, domácias ausentes; pecíolo 1,0-3,0 $\mathrm{mm}$ compr. Bótrio frondoso; ramos acessórios ausentes; brácteas semelhantes às folhas vegetativas em forma e diminuindo de tamanho; flores pediceladas, hipopódio ca. 2,0 mm compr., epipódio ca. $1,0 \mathrm{~mm}$ compr.; profilos ca. $9,0 \times 1,9 \mathrm{~mm}$, estreitoelípticos, ápice agudo, margem plana, ultrapassando o ápice do tubo floral; tubo floral 7,5-8,0 mm compr., oblongo, coberto por indumento denso-pubescente a hirsuto, esbranquiçado; sépalas 2,5-3,0 mm compr., triangulares, não ciliadas, não caudadas, com o mesmo indumento do tubo floral; segmentos do epicálice 2,6-3,1 mm compr., patentes, levemente achatados, do mesmo modo pilosos; corola ca. $3,5 \mathrm{~cm}$ diâm., rosaclara a rosa-choque, pétalas ca. $13 \mathrm{~mm}$ compr., elípticas; estames 18, pouco exsertos, porção livre dos filetes ca. 7,0 mm compr.; ovário ca. $1,8 \times 2,3 \mathrm{~mm}$, obtrapezoidal, glabro, estilete ca. $12 \mathrm{~mm}$ compr., óvulos 22-30. Cápsulas imaturas ca. 2,9×3,5 mm, arredondadas, não estipitadas; sementes ca. 4 .
Parátipo: BRASIL. Goiás: Alto Paraíso de Goiás, São Jorge, acesso ao Vale da Lua, $14^{\circ} 09^{\prime} 41^{\prime}$ 'S, 47046'15”'W, 28/II/1999, fl., Calago 97 (CEN, MO).

O hábito prostrado de Diplusodon chapadensis não é comum no gênero e pode ocorrer quando o indivíduo é submetido à passagem do fogo. Entretanto, caracteres como folhas estreito-elípticas, profilos longos ultrapassando o ápice do tubo floral, este oblongo, segmentos do epicálice deflexos a patentes e 18 estames, conjuntamente, a distinguem das demais espécies do gênero.

Por suas folhas eucamptódromas e estreitoelípticas, Diplusodon chapadensis pode ser confundida com D. macrodon, também da Chapada dos Veadeiros, que difere da primeira principalmente pelo indumento com tricomas estrelados densos, formando tufos, folhas revolutas, 12 estames e segmentos do epicálice com 5,5-7,0 cm de comprimento.

Populações de Diplusodon chapadensis foram encontradas em campo limpo, crescendo entre gramíneas, em campo sujo e em cerrado típico com Vellozia e Diplusodon alatus T.B. Cavalc., a

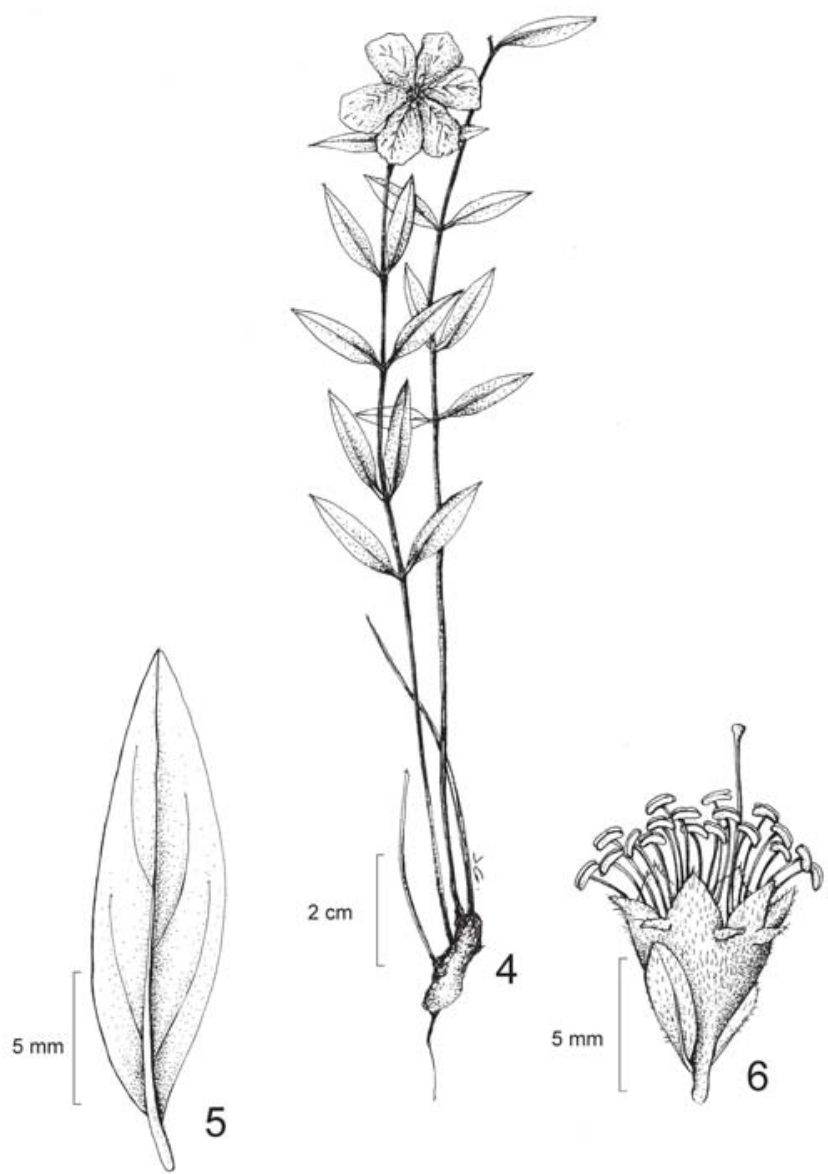

Figuras 4-6. Diplusodon chapadensis T.B. Cavalc. (Cavalcanti et al. 2185). 4. Hábito. 5. Folha, face abaxial. 6. Flor, retiradas as pétalas. (ilustrações elaboradas por Jeanito Sebastião Gentilini Filho). 
1.200 m s.n.m. As populações eram constituídas de poucos indivíduos isolados.

3. Diplusodon grahamae T.B. Cavalc., sp. nov. Tipo: BRASIL. Goiás: Água Fria de Goiás, estação repetidora da Telebrasília de Roncador, 12/VI/1993, fl., fr., G. Hatschbach \& E. Barbosa 59326 (Holótipo MBM).

Fig. 7-12

Foliis verticillatis ad congesto-decussata, sericeis, canescentibus, segmentis epicalycis patentibus ad deflexos, 12-15 staminibus distinguenda. Foliis linearibus vel angusto-elliptica, marginibus revolutis D. puberulus Koehne similis sed omnibus characteribus vegetativis et floralibus differt.

Arbustos 50-100 cm alt., eretos, ramificados. Ramos superiores cilíndricos, canescentes, não alados, hirsutos, tricomas brancos; internós 0,5-1,0 cm compr. Folhas 6-12×1,0-3,0 mm, verticiladas a decussadas, suberetas, eucamptódromas, seríceas, canescentes, coriáceas, subsésseis, lineares a estreito-elípticas, ápice obtuso, margem revoluta, base aguda; nervuras 1 de cada lado ao longo da nervura central, proeminentes; domácias presentes; pecíolo 0,5-1,0 mm compr.

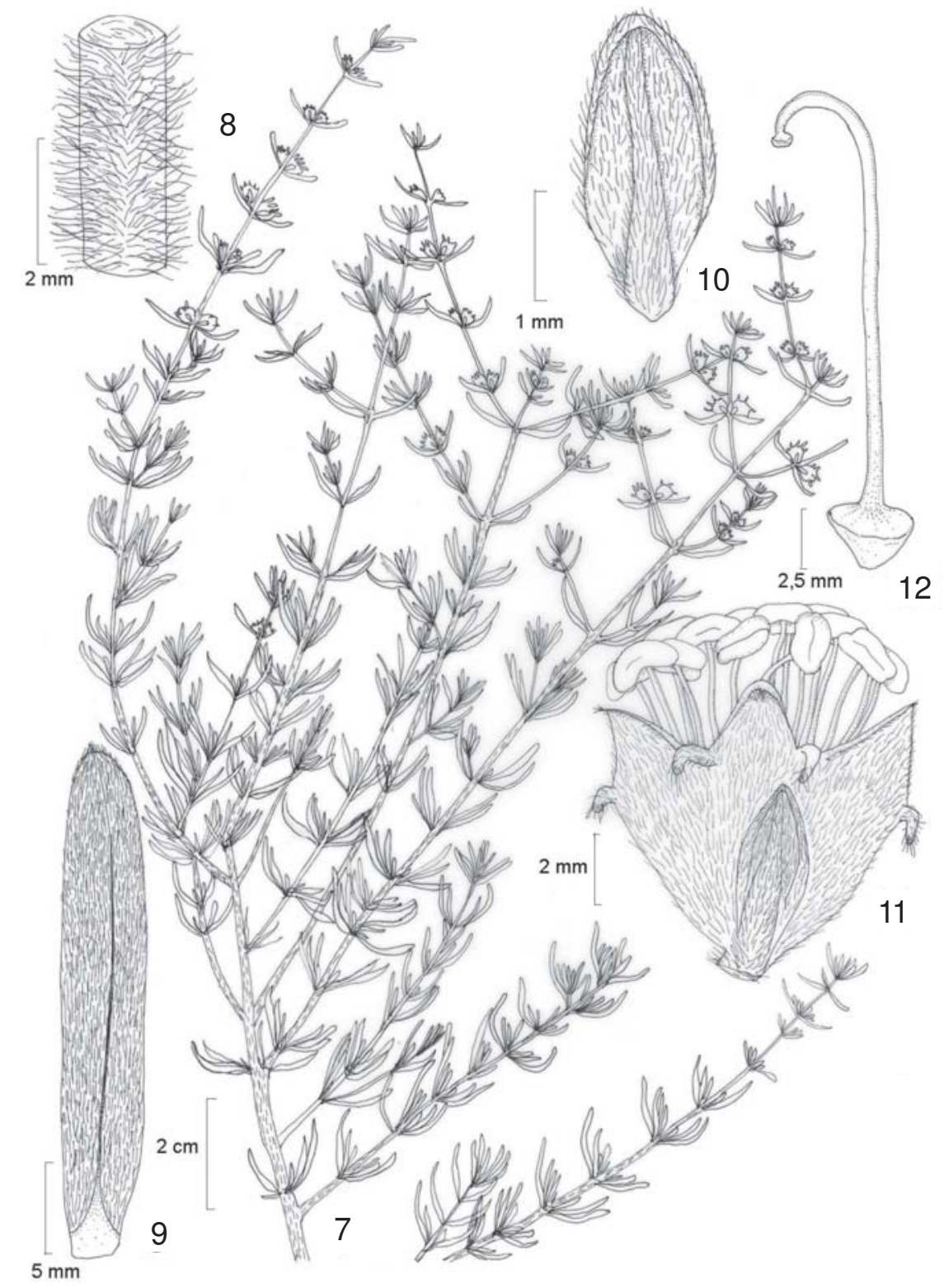

Figuras 7-12. Diplusodon grahamae T.B. Cavalc. (Hatschbach \& Barbosa 59326). 7. Ramo com inflorescência. 8. Detalhe do internó. 9. Folha, face adaxial. 10. Profilo, face adaxial. 11. Flor, retiradas as pétalas. 12. Pistilo (ilustrações elaboradas pela autora). 
Diplobótrio frondoso, florescência principal ca. $20 \mathrm{~cm}$ compr., paracládios 4,0-15 cm compr.; flores curtopediceladas, hipopódio ca. 1,0 mm compr., epipódio ca. 0,5; profilos 2,5-3,5×1,5 mm, obovais a lanceolados, ápice obtuso, margem involuta, alcançando a metade do tubo floral ou ultrapassando um pouco a metade do tubo floral; tubo floral 3,5-4,0 $\mathrm{mm}$ compr., infundibuliforme, coberto por tricomas curto-vilosos, apressos e ascendentes; sépalas 2,0-2,5 mm compr., triangulares, não caudadas, não ciliadas, esparsoseríceas; segmentos do epicálice 1,5-2,0 mm compr., cilíndricos, patentes a deflexos, menores que as sépalas, esparso-seríceos; corola ca. 2,5 cm diâm., rósea, pétalas $12-13 \times$ ca. 8,0 mm, elípticas, ápice obtuso, base obtusa; estames 12-15, pouco exsertos, ultrapassando as sépalas até $2,0 \mathrm{~mm}$, porção livre dos filetes 7,5-8,0 mm compr.; ovário 1,5-2,0×2,0-2,5 mm, obtrapezoidal, glabro, estilete 11-12 mm compr., óvulos 11-18. Cápsulas imaturas ca. 3,5×3,5 mm, obovais, não estipitadas; sementes ca. 8, 2,1×1,9 mm.

Parátipo: BRASIL. Goiás: Água Fria de Goiás, rodovia GO-118, subida para a torre repetidora de Roncador, 8/V/2000, fl., Hatschbach et al. 70676 (MBM).

No aspecto vegetativo, Diplusodon grahamae assemelha-se a D. puberulus Koehne (Minas Gerais e Bahia) e a D. rosmarinifolius A. St.-Hil. (Goiás e Distrito Federal), principalmente pelas folhas estreitoelípticas a lineares e com margens revolutas. Diplusodon puberulus diferencia-se pelas folhas com nervação hifódroma, indumento estrelado e tubo floral glabro, enquanto $D$. rosmarinifolius diferencia-se pelo indumento estrelado e segmentos do epicálice diminutos (ca. 0,5 mm de comprimento).

Diplusodon grahamae habita áreas de cerrado aberto com solo areno-pedregoso e de campos rupestres, a cerca de $1.200 \mathrm{~m}$ s.n.m.

O epíteto específico homenageia a Dra. Shirley A. Graham (Missouri Botanical Garden, Saint Louis, MO, E.U.A.), profunda conhecedora das Lythraceae, pela inestimável contribuição ao conhecimento desta família através de suas diversas publicações.

4. Diplusodon rupestris T.B. Cavalc., sp. nov. Tipo: BRASIL. Minas Gerais: São Roque de Minas, Cachoeira da Casca D' anta, parte de cima, 10/VII/ 1996, fl., J.N. Nakajima et al. 1941 (Holótipo CEN; isótipos HUFU, NY).

Fig. 13-16

Haec species nova Diplusodon hirsutus (Cham. \& Schlechtdl.) DC. indumento foliorum et florum, forma segmentorum epicalycis similis sed foliis eucamptodromis, 5-8-nervis in quoque latere nervi centralis, foliis et floribus maioribus, inflorescentia laxa, longa, bene procurrenti et 18 staminibus praeditis differt.

Subarbustos 50-70 cm alt., eretos, ramificados. Ramos superiores cilíndricos, castanhos, não alados, pubescentes; internós 3,0-7,5 cm compr. Folhas 20-57×10-30 mm, decussadas, suberetas, eucamptódromas, pubescentes a hirsutas, com tricomas esparsos, apressos na face adaxial, eretos na face abaxial, ovais, obovais, largo-elípticas, ápice obtuso, margem subrevoluta, base aguda, atenuada, raro obtusa; nervuras 5-8 de cada lado da nervura central, domácias ausentes; pecíolo 4,0-10 mm compr. Diplobótrio laxo, bracteoso, ramos acessórios ausentes, florescência principal 4,0-10 cm compr., paracládios 4,0-30 cm compr.; brácteas 10-20×4,0-9,0 mm; flores sésseis a subsésseis, hipopódio ausente, epipódio 0-0,5 mm

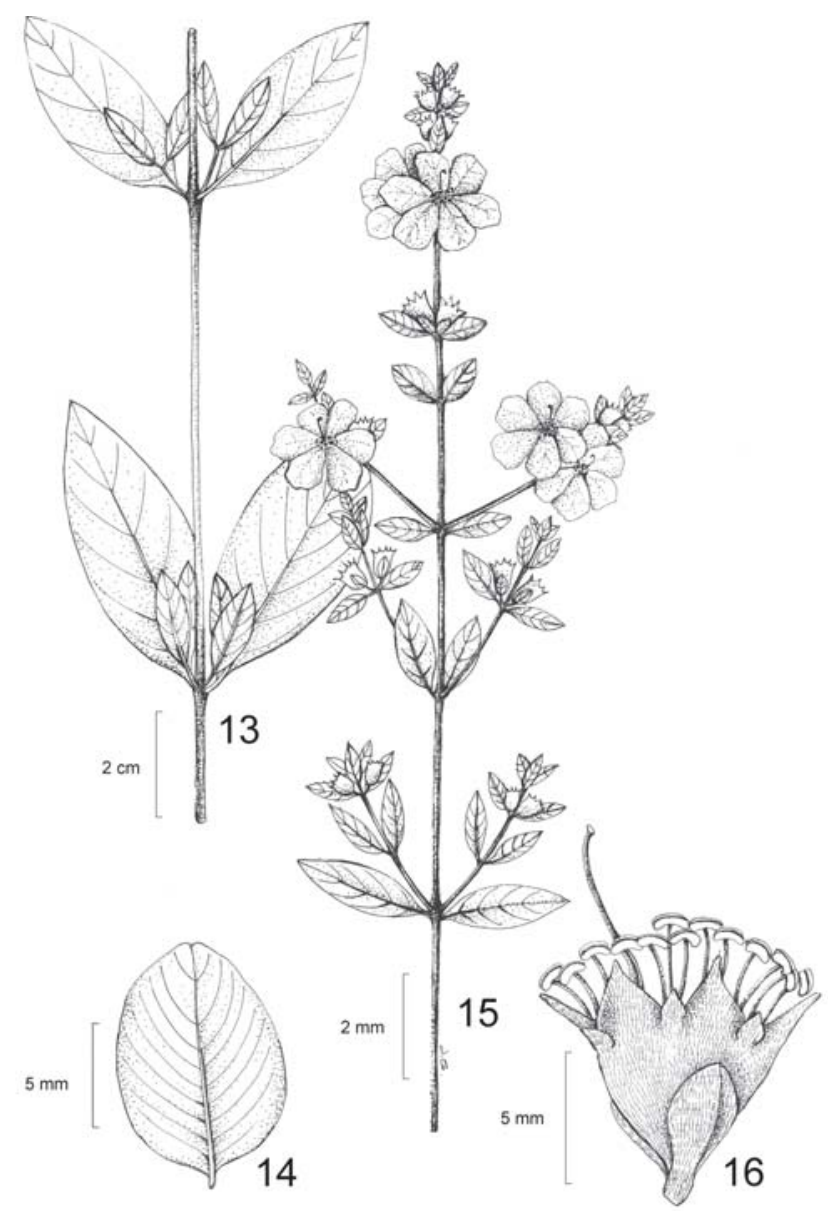

Figuras 13-16. Diplusodon rupestris T.B. Cavalc. (Nakajima et al. 1941). 13. Ramo vegetativo. 14. Folha, face adaxial. 15. Ramo com inflorescência. 16. Flor, retiradas as pétalas (ilustrações elaboradas por Jeanito Sebastião Gentilini Filho). 
compr.; profilos 3,5-6,0×2,0-2,5 mm, oblongos, carenados, alcançando menos da metade do tubo; tubo floral 4,0-6,0 mm compr., infundibuliforme, esverdeado a vináceo, seríceo a viloso; sépalas 2,5-2,8 mm compr., avermelhadas, não caudadas, vilosas, às vezes com tricomas glandulares; segmentos do epicálice 1,0-2,0 mm compr., eretos a patentes, lanceolados, vilosos; corola 2,0-2,5 cm diâm., lilás a arroxeada, pétalas $13 \times 10 \mathrm{~mm}$, largo-losangulares; estames 18 , exsertos ca. 2,0 mm, porção livre dos filetes 8,0-10 mm compr., rósea; ovário 2,1-3,5×2,5-3,5 mm, obtrapezoidal, glabro, estilete 15,5-16 mm compr., róseo, óvulos 18-29. Cápsulas não observadas.

Parátipos: BRASIL. Minas Gerais: Sacramento, Parque Nacional Serra da Canastra, 9/V/1995, fl., Romero et al. 2126 (CEN, HUFU); idem, próximo à guarita de Sacramento, 16/III/1995, fl., Romero et al. 1866 (CEN, HUFU); São Roque de Minas, estrada São Roque-Sacramento, próximo à torre de observação, 15/V/1995, fl., Nakajima et al. 1113 (CEN, HUFU); idem, próximo à guarita de Sacramento, Parque Nacional da Serra da Canastra, 21/IV/1997, fl., Romero et al. 4218 (CEN, HUFU); trilha para a guarita de baixo, Cachoeira da Casca D'anta, 10/VII/1996, fl., Nakajima et al. 1958 (CEN, HUFU); Cachoeira Casca D'Anta, PARNA Serra da Canastra, São Roque de Minas, 17/VII/1995, fl., Romero et al. 2509 (CEN, HUFU).

Diplusodon rupestris assemelha-se a $D$. hirsutus pelo tipo de indumento das folhas e flores, além do formato dos segmentos do epicálice. Diferem pelas características diagnósticas principais de $D$. hirsutus, que são as folhas com 3-4 nervuras de cada lado da nervura central, folhas menores, com 6-35 mm de comprimento e 5-25 $\mathrm{mm}$ de largura, flores maiores, com tubo floral de 2-2,5 $\mathrm{mm}$ de comprimento, inflorescência frondosa, congesta, e androceu com 12-15 estames.

Espécie endêmica dos campos rupestres e campos limpos do Parque Nacional da Serra da Canastra, no sul do Estado de Minas Gerais. Floresce de maio a julho, neste último mês encontrada com alguns frutos imaturos.

\section{Agradecimentos}

A autora agradece à Embrapa Recursos Genéticos e Biotecnologia, pela infra-estrutura para as expedições de coleta; ao $\mathrm{CNPq}$, pelo apoio a esta pesquisa, através da bolsa PQ n. 300976/95-0; ao Glocimar Pereira da Silva e Aécio Amaral dos Santos, pelo auxílio na coleta de exemplares; ao Dr. Jimmi Nakajima, pelo envio de espécimes de Lythraceae da Serra da Canastra, Minas Gerais; ao Dr. Tarciso Filgueiras, pela elaboração das diagnoses em latim; ao Jeanito Sebastião Gentilini Filho, pelas ilustrações de Diplusodon chapadensis e D. rupestris.

\section{Referências bibliográficas}

Cavalcanti, T.B. 2004. Novos táxons, novos status, novo sinônimo e lectotipificações em Diplusodon Pohl (Lythraceae). Boletim de Botânica da Universidade de São Paulo 22(1): 1-13.

Cavalcanti, T.B. \& Graham, S.A. 1996. Diplusodon bolivianus sp. nov. (Lythraceae), the first report of the genus for Bolivia. Novon 6(3): 253-255.

Cavalcanti, T. B. \& Graham, S.A. 2005. New taxa in Lythraceae from Latin America. Novon 15(1): 59-68. 